\title{
Effect of the addition of waste basalt fibers on concrete shrinkage
}

\author{
Tomasz Kowalik , and Andrzej Ubysz \\ Wroclaw University of Science and Technology, Wybrzeże Wyspiańskiego 27, 50370 Wrocław
}

\begin{abstract}
This article presents the issues related to using by-products and waste materials in constructionand mining industry. The current applications of selected materials in various areas are presented, with particularfocus on cases in the construction and mining industries, where waste-based composites sealed with various hydraulic binders are used to build new structural elements or just as fills and backfills. In the next part of the revivew, the methodology and selected results of shrinkage tests on concrete composite samples with the addition of various amounts of additives and price tests to reference samples without dispersed reinforcement are presented and discussed. Research has been carried out on the subject of balance between concrete and the semi-finished product used.
\end{abstract}

\section{Introduction - general description of the facility}

The growing demand for infrastructure and the increasing prices of building materials cause interest in new technological solutions as well as create opportunities for reusing previously produced building materials [1-5]. Steel fibres [1,2], PET [3], waste basalt rebars [4-5] and even rubber from used tyres [6,7] may be used to improve selected characteristics of composite materials in building and civil engineering. Potential reuse of CDW (construction demolition waste) is one of the leading areas of sustainable development [8] in construction and mining industry [9]. Reuse of spoil material and by-products Semm to be extremly attractive idea for mining industry that produces a lot of waste and needs large amounts of backfill material for safe mining production [10-12]. In addition to the economic aspects [11$12]$, in some cases special attention should be paid to the durability of reused materials $[13,14]$ as well as health aspects. At the same timeregulations are being raised all over the world, imposing on companies and investors the use of recycled or reused building materials. Currently, there is a lot of research conducted on replacing the materials traditionally used so far as an intermediate, e.g. for the production of concrete mix, with alternative ones. Ubysz and Luszczyk are conducting research on the possibility of using steel fibers from recycled tires as reinforcement for concrete as well as the use of other materials as reinforcing fibers $[6,7]$. In the next step researchers undertake the replacement of the seemingly indispensable component of concrete, which is aggregate, with waste composite rods [5]. Another example of attempts to replace cement binder is making mixtures based on industrial wastes dissolved in water [15].

Corresponding author: tomasz.kowalik@pwr.edu.pl 
In addition to the use of recycled materials as semi-finished products for concrete mix, research is also conducted on the possibility of using it in the other areas. Apart from the widespread use of pieces of rubber from car tires as filling in artificial surfaces of football fields or in communication construction [6,7], research is conducted on the possibility of using construction waste in geotechnics and miningwith particular emphasis on the lack of negative environmental impact $[9-11,15]$.

The article presents selected results of tests carried out on concrete samples with the addition of waste basalt fibers used as dispersed reinforcement.

\section{Shrinkage of concrete composites - conditions}

Concrete shrinkage is an intrinsic phenomenon that occurs in materials with a porous structure [16,17]. It consists in reducing the volume of concrete through the loss of water contained in the pores due to physical and chemical phenomena. The total volume change of concrete consists of chemical and autogenous shrinkage resulting from the processes of setting and hardening of the cement slurry and deformations caused by the loss of water from the material (plastic shrinkage and drying out). One of the main factors determining concrete shrinkage is the thermal and humidity conditions of the environment [18]. All those factors must be considered in constitutive modelling of composites based on hydraulic cementous binders [19].

As a porous material concrete is exposed to the risk of reducing its volume. In nonlaboratory conditions, it is inevitable and the effects of its formation can only be limited [20]. In the process of designing fibro-concrete, a number of factors should be taken into account that affect the most important strength properties of the finished concrete as well as shrinkage. Below are some issues that should be taken into account when designing a concrete mix with added fibers [21] :

- the maximum grain diameter should not be greater than $1 / 3$ of the length of the straight fibers and not more than $1 / 2$ of hook-shaped fibers,

- maximum grain diameter should not exceed 4 or $8 \mathrm{~mm}$.

- due to the deterioration of the workability of the concrete mix, it is necessary to use a plasticizing admixture. Its absence may result in increased porosity of concrete and uneven distribution of fibers,

- $\quad$ water-cement ratio should not exceed 0.55.

Common practices to reduce the effects of shrinkage in structural elements are the placement of additional reinforcement at the surface of the element and the use of appropriately designed concrete mixtures. The most common is steel and polypropylene dispersed reinforcement. Polypropylene reinforcement is used to eliminate the effects of autogenous shrinkage occurring during the drying of the cement. The tests of concretes with polypropylene fibers show that the increase in the volume of the fiber in the concrete in the amount of $0.25,0.5$ and $0.75 \%$ reduces the autogenous shrinkage gradually by 5,15 and $26 \%$ compared to normal concrete will shrink after 24 hours. Steel reinforcement also is used to eliminate the effects of shrinkage from drying out. Combined polypropylene and steel reinforcement is increasingly used. This combination eliminates both autogenic shrinkage and drying out. In many cases composite reinforcement (carbon, basalt) is also used, which has no undesirable properties in some situations, such as the risk of corrosion in aggressive environments, interference with the electromagnetic field in the vicinity of precise devices. 


\section{Sample preparation}

Concrete shrinkageas a physical phenomenon, occurs due to the loss of free water from the concrete, as well as occurs in fiberconcrete [21]. Basalt fibers reduce shrinkage due to the fact that they do not shrink themselves, and thus they resist concrete shrinkage due to the adhesion effect between these materials. As the number of fibers increases, the shrinkage decreases, although it is not proportional. Too little amount of fibers does not, or only slightly affects, the amount of shrinkage. On the other hand, too much fiber causes difficulties in workability and arrangement of the concrete mix.

The concrete mix was made in the Accredited Test Laboratory located at the Faculty of Civil Engineering at the Wrocław University of Technology. In the first stage all the components of the concrete mixture were mixed and then basalt fibers were added (figures $1 \mathrm{a}, 1 \mathrm{~b})$. Then the ready mixture was placed in $100 \times 100 \times 500 \mathrm{~mm}$ molds and stored until demoulding.

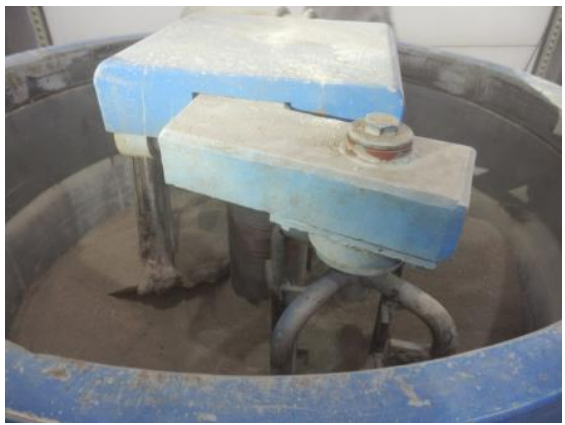

Fig. 1a Mixing of ingridients

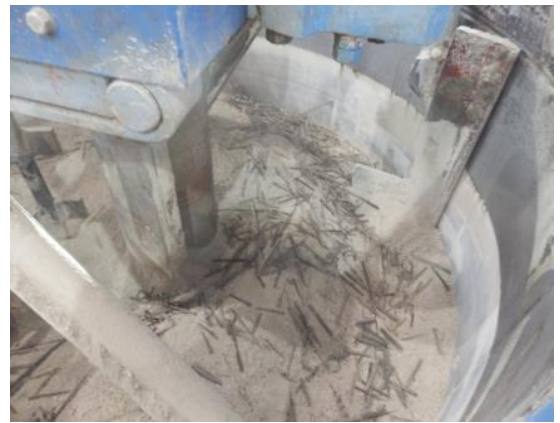

Fig. 1b Mixing of ingridients with basalt fibers

The sample shrinkage was tested on the basis of the PN-84: B-06714/23 standard. Determination of volumetric changes by the Amsler method. It consists the change in the length of the sample, determined with the Amsler apparatus, in relation to its initial length. The test was carried out on bars with dimensions of $100 \times 100 \times 500 \mathrm{~mm}$ made by using aggregates with a grain size not greater than $16 \mathrm{~mm}$ according to the recipe in tab 1 .

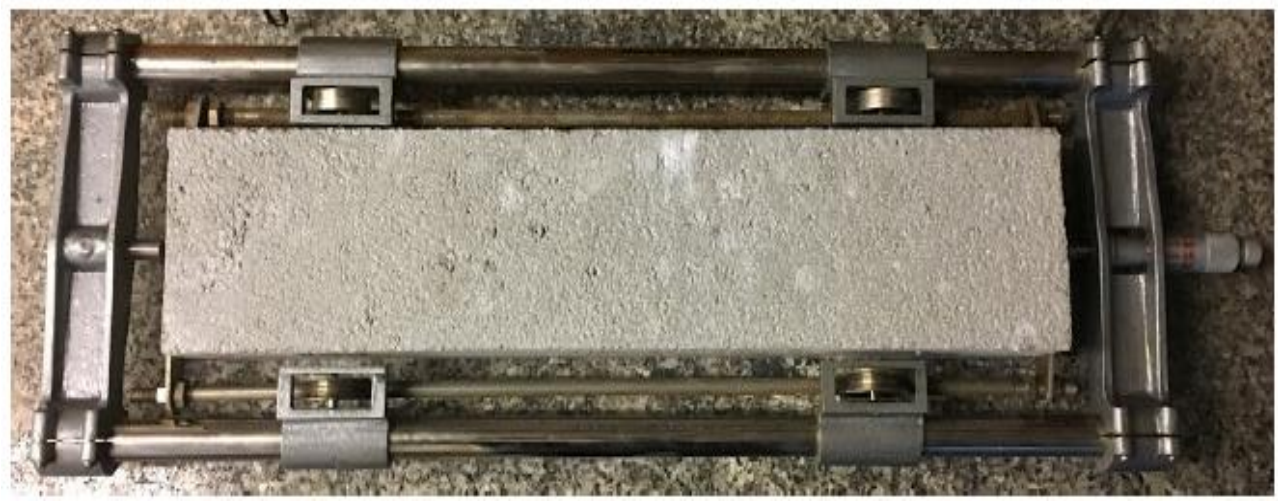

Fig. 2. Sample with measuring instrument 
Table 1. The proportions of the ingredients used to make the concrete mix

\begin{tabular}{|c|c|c|c|c|c|c|}
\hline \multirow[b]{2}{*}{ Ingredient } & Cement & \multicolumn{3}{|c|}{ Aggregate } & \multirow[b]{2}{*}{ Water } & \multirow{2}{*}{$\begin{array}{l}\text { Fluidizing } \\
\text { admixture }\end{array}$} \\
\hline & $\begin{array}{c}\text { CEM II } \\
32,5\end{array}$ & $0-2 \mathrm{~mm}$ & $2-8 \mathrm{~mm}$ & $8-16 \mathrm{~mm}$ & & \\
\hline quantity $\left[\mathrm{kg} / \mathrm{m}^{3}\right]$ & 450 & 670 & 500 & 600 & 180 & 22,5 \\
\hline
\end{tabular}

After concreting, the molds with bars were placed in a climatic chamber with a temperature of $18 \pm 2 \mathrm{oC}$ and a relative humidity of over $90 \%$. The samples were demoulded 24 hours after concreting. Then the samples were stored in a climatic chamber at a temperature of $18 \pm 2{ }^{\circ} \mathrm{C}$ and a relative air humidity of $65-75 \%$. The samples were stored in a way that allowed air to enter from all sides (Figure 3).

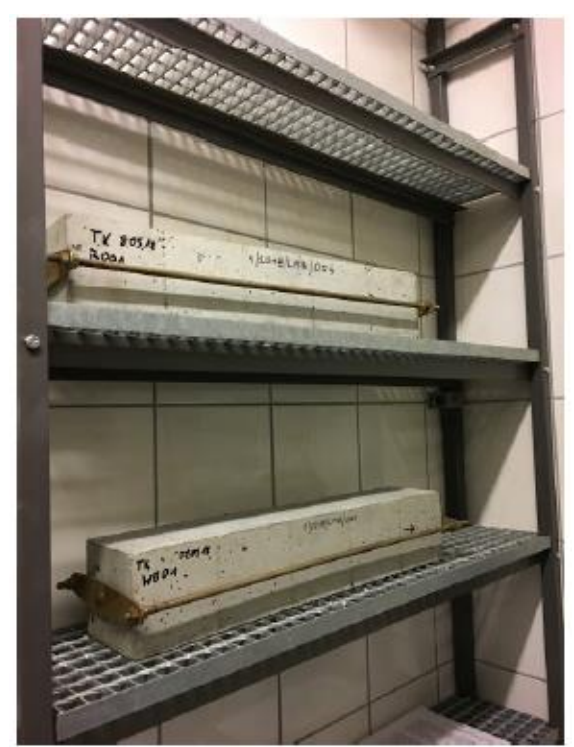

Fig. 3. Samples in a climatic chamber

The change in beams length after $\mathrm{n}$ days was calculated according to the formula (1):

$$
\epsilon_{n}=\frac{\left(l_{n}-l_{1}\right) \cdot 1000}{500}
$$

where: $\quad 1_{n}-$ sample measurement result after time $n$, in $\mathrm{mm}$,

$l_{1}$ - the result of the first sample measurement after $24 \mathrm{~h}$ of hardening, in $\mathrm{mm}$.

\section{Results}

The table presents selected results of the tests carried out for selected samples with the content of basalt fibers in the amount of $2 \%$.

The figure 5 presents a collective graph comparing the shrinkage of samples with the addition of basalt fibers in the amount of $1 \%, 2 \%$ and without the addition of fibers. By analyzing the chart it can be concluded that the lowest final shrinkage was found for the samples with the highest percentage content. Practically from the beginning of the measurements, clearly lower values of the results for particular days can be noticed compared to other samples. Considering the results for the tested samples, it can be seen that the final 
value of shrinkage for samples with the addition of basalt fibers in the amount of $2 \%$ is lower than the samples without the addition of fibers by about $65 \%$. The highest deformations occur in the time interval up to the 28 day from the moment of performing the reference measurement. This is in line with theories suggesting that concrete should be cared for in the constructed structures and with the achievement of its full strength. The study was terminated after 165 days due to the very slight deformation that appeared after 84 days.

Table 2. Shrinkage test results

\begin{tabular}{|c|c|c|c|c|c|c|c|c|}
\hline Number of & Time & \multicolumn{2}{|c|}{ Readings } & \multicolumn{2}{|c|}{ Readings after time } & \multirow{2}{*}{$\begin{array}{c}\text { Readings } \\
\text { correction }\end{array}$} & \multirow{2}{*}{$\begin{array}{c}\text { Result of the } \\
\text { research }\end{array}$} & \multirow{2}{*}{$\begin{array}{c}\text { Result of the } \\
\text { research - } \\
\text { average score }\end{array}$} \\
\hline- & days & template & sample & template & sample & & & \\
\hline BW2001 & \multirow{3}{*}{0} & & 11,54 & \multirow{3}{*}{ - } & - & \multirow{3}{*}{-} & - & \multirow{3}{*}{-} \\
\hline BW2002 & & & 10,64 & & - & & - & \\
\hline BW2003 & & & 10,77 & & - & & - & \\
\hline BW2001 & \multirow{3}{*}{5} & & 11,54 & \multirow{3}{*}{6} & 11,51 & \multirow{3}{*}{ - } & $-0,06$ & \multirow{3}{*}{$-0,0533$} \\
\hline BW2002 & & & 10,64 & & 10,75 & & 0,22 & \\
\hline BW2003 & & & 10,77 & & 10,61 & & $-0,32$ & \\
\hline BW2001 & \multirow{3}{*}{7} & & 11,54 & \multirow{3}{*}{6} & 11,5 & \multirow{3}{*}{-} & $-0,08$ & \multirow{3}{*}{$-0,0667$} \\
\hline BW2002 & & & 10,64 & & 10,75 & & 0,22 & \\
\hline BW2003 & & & 10,77 & & 10,6 & & $-0,34$ & \\
\hline BW2001 & \multirow{3}{*}{14} & & 11,54 & \multirow{3}{*}{6} & 11,49 & \multirow{3}{*}{ - } & $-0,1$ & \multirow{3}{*}{$-0,0800$} \\
\hline BW2002 & & & 10,64 & & 10,74 & & 0,2 & \\
\hline BW2003 & & 6 & 10,77 & & 10,6 & & $-0,34$ & \\
\hline BW2001 & \multirow{3}{*}{21} & 0 & 11,54 & \multirow{3}{*}{6} & 11,47 & \multirow{3}{*}{ - } & $-0,14$ & \multirow{3}{*}{$-0,1200$} \\
\hline BW2002 & & & 10,64 & & 10,72 & & 0,16 & \\
\hline BW2003 & & & 10,77 & & 10,58 & & $-0,38$ & \\
\hline BW2001 & \multirow{3}{*}{28} & & 11,54 & \multirow{3}{*}{6} & 11,43 & \multirow{3}{*}{ - } & $-0,22$ & \multirow{3}{*}{$-0,2067$} \\
\hline BW2002 & & & 10,64 & & 10,68 & & 0,08 & \\
\hline BW2003 & & & 10,77 & & 10,53 & & $-0,48$ & \\
\hline BW2001 & \multirow{3}{*}{84} & & 11,54 & \multirow{3}{*}{6} & 11,41 & \multirow{3}{*}{ - } & $-0,26$ & \\
\hline BW2002 & & & 10,64 & & 10,65 & & 0,02 & $-0,2600$ \\
\hline BW2003 & & & 10,77 & & 10,5 & & $-0,54$ & \\
\hline BW2001 & & & 11,54 & & 11,39 & & $-0,3$ & \\
\hline BW2002 & 165 & & 10,64 & 6 & 10,63 & - & $-0,02$ & $-0,2933$ \\
\hline BW2003 & & & 10,77 & & 10,49 & & $-0,56$ & \\
\hline
\end{tabular}

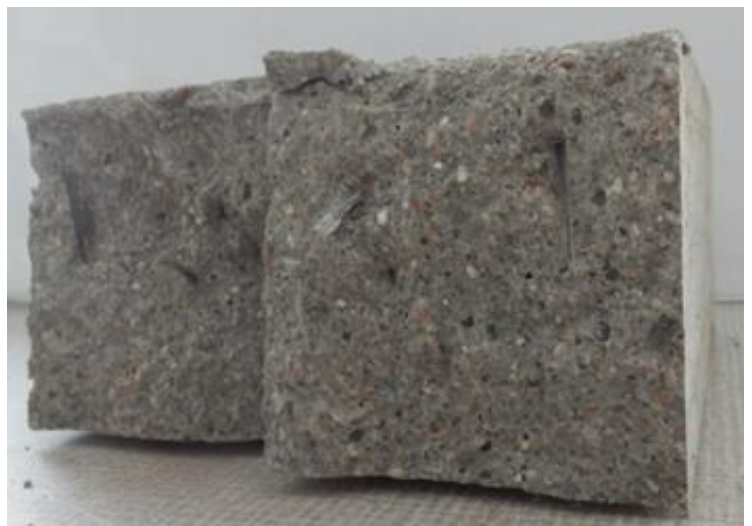

Fig. 4a Cross-section of the sample

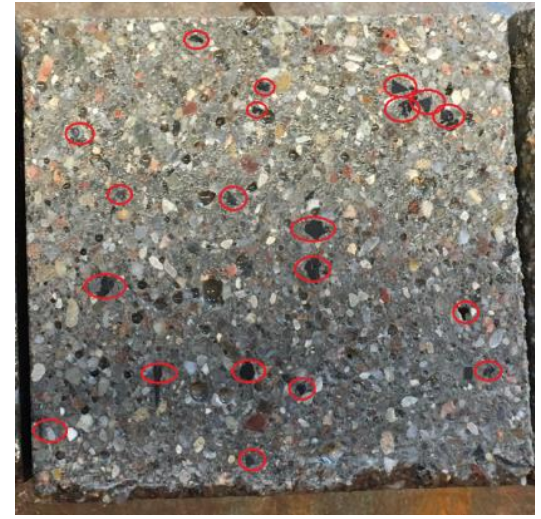

Fig. 4b Cross-section of the sample 
After the raw material tests, the bending tensile strength test was also carried out. A side effect, albeit a desirable one, was the possibility of checking the distribution of fibers in the sample's cross-section. The photo $4 \mathrm{a}$ and $4 \mathrm{~b}$ shows a cross-section through a damaged sample with marked fibers. Aforementioned fibers are evenly distributed across the crosssection, which also resulted in lower deformation of the tested samples.

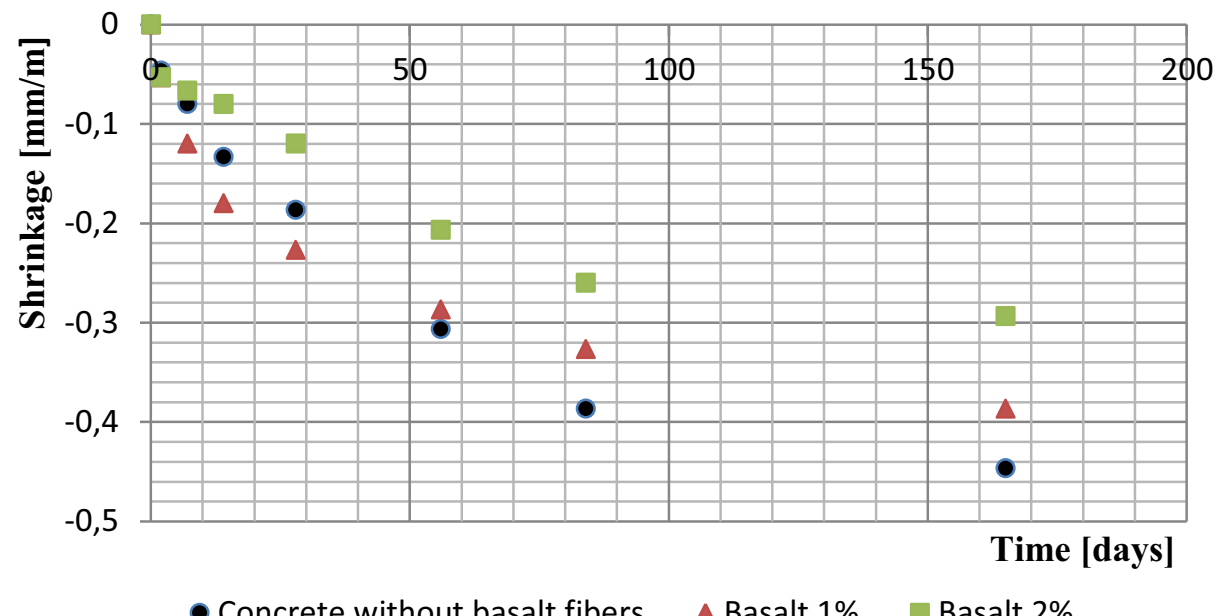

Fig. 5. Shrinkage of concrete samples - the results of the tested ones

\section{Conclusions}

Based on the conducted research it can be concluded that waste basalt fibers fulfill their role in the process of reducing the negative effects of shrinkage. The decrease in shrinkage stress over time for $2 \%$ fibers from the start is much lower than for samples with $1 \%$ and without added fibers. Considering the final recorded result of shrinkage stresses for samples with a content of $2 \%$ compared to samples without the addition of reinforcement, a decrease in the total shrinkage strains by about $65 \%$ can be noted. When making the concrete mix, it was found that the maximum amount of added fibers should fluctuate around $2 \%$. With a larger amount, there were significant difficulties in workability, which consequently led to problems with the arrangement of the mixture in the molds and the exact vibration of the samples.

\section{References}

1. A. Karimipour, M. Ghalehnovi, J. de Brito, Mechanical and durability properties of steel fibre-reinforced rubberised concrete. Construction and Building Materials, 257,119463 (2020)

2. S.P. Eronko, S.M. Gorbatyuk, E.V. Oshovskaya, B.I. Starodubtsev, New Engineering Solutions in Creation of Mini-BOF for Metallic Waste Recycling. IOP Conf. Ser.: Mat. Sci. Eng., 287(1), 012004 (2018)

3. D. Foti, Preliminary analysis of concrete reinforced with waste bottles PET fibers. Construction and Buildings Materials, 25, 1906-1915 (2011) 
4. T. Kowalik, D. Logon, A. Ubysz, Feasibility study of the utilization of waste basalt rebars as fibre reinforcement for concrete. MATEC Web Conf., 251 (2018)

5. A. Yazdanbakhsh, L.C. Bank, C. Chen, Use of recycled FRP reinforcing bar in concrete as coarse aggregate and its impact on the mechanical properties of concrete. Construction and Building Materials, 121, 278-284 (2016)

6. A. Duda, D. Sobala, T. Siwowski, D. Kaleta, The use of recycled material from car tires in road construction. Archives of Institute of Civil Engineering, 21, 97-111 (2016) (in Polish)

7. A. Duda, M. Kida, S. Ziembowicz, P. Koszelnik, Application of material from used car tyres in geotechnics - an environmental impact analysis. PeerJ, 8, e9546 (2020)

8. A. Myaskov, I. Temkin, S. Deryabin, D. Marinova, Factors and Objectives of Sustainable Development at the Implementation of Digital Technologies and Automated Systems in the Mining Industry. E3S Web Conf., 174, 04023 (2020)

9. Ch. Kongar-Syuryun, A. Ivannikov, A. Khayrutdinov, Y. Tyulyaeva, Geotechnology using composite materials from man-made waste is a paradigm of sustainable development. Materials Today: Proceedings 38: 2078-2082, (2021)

10. Ch. Kongar-Syuryun, Y Tyulyaeva, A. Khairutdinov, T. Kowalik,Industrial waste in concrete mixtures for construction of underground structures and minerals extraction. IOP Conf. Ser.: Mater. Sci. Eng.,869, 032004 (2020)

11. J. Rybak, S.M. Gorbatyuk, K.Ch. Bujanovna-Syuryun, A.M. Khairutdinov, Yu.S. Tyulyaeva, P.S. Makarov, Utilization of Mineral Waste: A Method for Expanding the Mineral Resource Base of a Mining and Smelting Company.Metallurgist,64, 851-861 (2021)

12. J.M. Rybak, Ch. Kongar-Syuryun, Yu. Tyulyaeva, A.M. Khayrutdinov, I. Akinshin. Geomechanical substantiation of parameters of technology for mining salt deposits with a backfill. Mining Science, 28, 19-32 (2021)

13. M. Maj, F. Grzymski, A. Ubysz, The loss of durability in reinforced concrete structures. Journal of Physics: Conference Series, 1425(1), 012207 (2020)

14. E. Henin, R. Tawadrous, G. Morcous, Effect of surface condition on the bond of Basalt Fiber-Reinforcement Polymer bars in concrete. Construction and Building Materials, 226, 449-458 (2019)

15. M.M. Khayrutdinov, C.B. Kongar-Syuryun, Y.S. Tyulyaeva, A.M. Khayrutdinov, Cementless backfill mixtures based on water-soluble manmade waste. Bulletin of the Tomsk Polytechnic University. Geo Assets Engineering, 331(11), 30-36 (2020)

16. R. Balevičius, M. Augonis, The effects of bond, shrinkage and creep on cracking resistance of steel and GFRP RC members. Composite Structures, 187, 85-101 (2018)

17. M. Kheradmand, Z. Abdollahnejad, F. Pacheco-Torgal, Drying shrinkage of fly ash geopolymeric mortars reinforced with polymer hybrid fibres. Proceedings of Institution of Civil Engineers: Construction Materials, 173(1), 28-40 (2020)

18. M. Khan, M. Cao, M. Ali, Cracking behaviour and constitutive modelling of hybrid fibre reinforced concrete. Journal of Building Engineering, 30, 101272 (2020)

19. J. Michalek, Variation in compressive strength of concrete aross thickness of placed layer. Materials, 12(13), 2162 (2019)

20. M.A. Glinicki,Assessment and design of fibro-concrete based on equivalent strength. Drogi i Mosty, 3(2002) (in Polish)

21. J. Jasiczak, P. Mikołajczyk,Technology of concrete modified with admixtures and additives. Oficyna Wydawnicza Politechniki Poznańskiej, Poznań 2003 (in Polish) 